\title{
O oficial de justiça e a sociedade 4.0
}

\author{
The bailiff and the society 4.0 \\ El oficial de justicia y la sociedad 4.0
}

Recebido: 15/08/2021 | Revisado: 22/08/2021 | Aceito: 26/08/2021 | Publicado: 28/08/2021

Roberto Magno Reis Netto
ORCID: https://orcid.org/0000-0002-5076-6149
Universidade Federal do Pará, Brasil
Faculdade da Amazônia, Brasil
E-mail: bob_reis_ufpa@ yahoo.com.br
Wando Dias Miranda
ORCID: https://orcid.org/0000-0003-1630-6736
Secretaria de Estado de Segurança Pública, Brasil
Faculdade da Amazônia, Brasil
E-mail: wandomiranda @ outlook.com
Clarina de Cássia da Silva Cavalcante
ORCID: https://orcid.org/0000-0003-2051-0211
E-mail: clarinacavalcante@ outlook.com

\section{Resumo}

O presente artigo, teve como objetivo descrever as possíveis funções e perspectivas a serem assumidas pelos oficiais de justiça no seio das sociedades 4.0. O estudo pautou-se num método indutivo e intuitivo, mediante pesquisa documental voltada à projetos de lei, proposições locais e possíveis novas atribuições pensadas para a categoria. Verificou-se que, para além das propostas legislativas e iniciativas locais atualmente identificadas, a integração dos oficiais de justiça à novas atividades (como a de inteligência judicial e de execução de novas formas de constrição patrimonial) poderia representar a evolução desta categoria para um novo patamar útil ao judiciário e sociedade. Mais ainda, os oficiais poderiam revolver ao seu passado e reincorporar funções típicas da área da segurança e defesa, atendendo, assim, às necessidades decorrentes da determinação do CNJ de instituição das polícias judiciais, alçando estes agentes à uma nova categoria de servidores públicos especializados na execução material de ordens judiciais.

Palavras-chave: Oficiais de justiça; Sociedade 4.0; Novas atribuições.

\begin{abstract}
This article aimed to describe the possible roles and perspectives to be assumed by bailiffs within societies 4.0. The study was based on an inductive and intuitive method, through documentary research focused on bills of law, local proposals and possible new attributions designed for the category. It was found that, in addition to the currently identified legislative proposals and local initiatives, the integration of bailiffs to new activities (such as judicial intelligence and the execution of new forms of patrimonial constriction) could represent the evolution of this category to a new useful level for the judiciary and society. Furthermore, the officers could go back to their past and reincorporate typical functions in the area of security and defense, thus meeting the needs arising from the determination of the $\mathrm{CNJ}$ to institute judicial police, raising these agents to a new category of public servants specialized in material execution of court orders.
\end{abstract}

Keywords: Bailiffs; Society 4.0; New assignments.

\section{Resumen}

Este artículo tuvo como objetivo describir los posibles roles y perspectivas a ser asumidos por los funcionarios de justicia dentro de las sociedades 4.0. El estudio se basó en un método inductivo e intuitivo, a través de una investigación documental centrada en proyectos de ley, propuestas locales y posibles nuevas atribuciones diseñadas para la categoría. Se encontró que, además de las propuestas legislativas e iniciativas locales actualmente identificadas, la integración de los alguaciles a nuevas actividades (como la inteligencia judicial y la ejecución de nuevas formas de constricción patrimonial) podría representar la evolución de esta categoría hacia una nueva utilidad. nivel para el poder judicial y la sociedad. Además, los agentes podrían volver a su pasado y reincorporarse a funciones típicas en el área de seguridad y defensa, atendiendo así las necesidades derivadas de la determinación del CNJ de instituir policías judiciales, elevando a estos agentes a una nueva categoría de servidores públicos. especializada en ejecución material de órdenes judiciales.

Palabras clave: Oficiales de justicia; Sociedad 4.0; Nuevas asignaciones. 


\section{Introdução}

Como um mantra, repete-se em muitos veículos de comunicação que, num curto período de tempo, muitas funções e empregos hoje existentes, ou se sujeitarão a transformações intensas, readequando seu funcionamento e peculiaridades às novas dinâmicas do Século XXI, ou, simplesmente, deixarão de existir, sendo substituídos pela atuação de outros profissionais mais abrangentes, ou, até mesmo, por novas expressões da tecnologia, como a inteligência artificial (Peck \& Rocha, 2018).

De fato, pode-se observar que o processo de transformação das sociedades, que se intensificou após o surgimento da pandemia de COVID-19, em 2020, obrigou o ser humano a adotar novos níveis de interação social on line, bem como, transformou o exercício de muitas atividades por meio de práticas como o home office (trabalho doméstico) e o BYOD - bring your own device (traga seu próprio dispositivo para o ambiente de trabalho), ressignificando (e precarizando) noções como jornada de trabalho, hierarquia, habitualidade, dentre outros. De outro lado, essa mesma sociedade tecnológica e de intensas transformações, assistiu ao agravamento do abismo da desigualdade social anteriormente existente, com a ampliação da pobreza, sobretudo, no seio de um contingente populacional sem efetivo acesso aos benefícios dessas novas dinâmicas, e, portanto, relegado a um contexto de empregos e funções do Século XX, quando não, à total informalidade, bem como, a uma situação de usufruto marginal das novas tecnologias (mediante o acesso, talvez, à equipamentos mais baratos e bem menos confiáveis).

A então nominada exclusão social, também em transformação conjuntamente às sociedades, mostrou uma nova faceta: a da exclusão digital. Essa exclusão, por sua vez, se expressa pela inacessibilidade material de milhões de cidadãos aos frutos mais básicos das novas tecnologias, como, por exemplo, diz respeito ao contingente de pessoas sem acesso à internet: “O percentual de domicílios que utilizavam a Internet subiu de 74,9\% para 79,1\%, de 2017 para 2018 [...]”, representando um total de 20,9\% de domicílios estimados sem qualquer acesso, ao passo que "[...] o rendimento médio per capita daqueles em que havia utilização da Internet era quase o dobro do rendimento dos que não utilizavam a rede" (IBGE, 2019, não paginado).

Para além da exclusão do acesso à internet e tecnologias, ainda, há que se falar na impossibilidade de adequação de pessoas às dinâmicas do novo mundo, diante do qual trabalhadores pouco capacitados, correspondentes ao mesmo contingente já naturalmente excluído das fileiras do mercado formal de trabalho da atualidade, certamente, se verão atingidos diretamente pela transformação das novas tecnologias, sendo cada vez mais afastados das possibilidades de integração à economia (Souza \& Oliveira, 2019), num círculo vicioso de reiteração da pobreza.

Neste mundo, portanto, surgem novos desafios para os estados-nação, quanto ao enfrentamento de problemas de proporções mundiais e diretamente ligados aos incomensuráveis fluxos da economia global, porém, cujos efeitos negativos são sentidos nas escalas locais das cidades e países. As políticas públicas, portanto, devem observar para além da escala das necessidades locais, os fluxos de integração e desintegração das economias regionais, e, de que forma eles atingem o território em que as mesmas devem ser realizadas. E, mais ainda, devem buscar fundamento na enxurrada de dados diariamente produzidos nas esferas públicas e privada, porém, sem olvidar que existe a já referida gama de cidadãos alijados das estatísticas do big data.

Nessa perspectiva, muito se tem discutido a respeito da transformação do poder judiciário e dos desafios que ele vivencia, sob diversas perspectivas: o uso da inteligência artificial para julgamento de processos; a mensurabilidade fragilizadora do poder judiciário, pela ação de agentes econômicos (como grandes escritórios e start up’s); a necessidade de implantação e a resistência à novas tecnologias; e, as necessidades de integração da população mais pobre a essa justiça tecnológica, como garantia de acesso à justiça. Afinal, para além dos benefícios inegáveis da informatização do poder judiciário que se tem observado, sobretudo, após a pandemia de COVID-19, de outro lado, pouco se discute sobre como fazer essa justiça chegar às áreas mais pauperizadas, onde sequer os sinais telefônicos funcionam com a devida qualidade.

Nesta toada, o presente artigo propôs reflexões em torno de um sujeito processual constante (ou seja, um sempre 
presente nas relações processuais), cuja atuação, externa aos muros das repartições por natureza, pode assumir novos papéis e perspectivas na era tecnológica, contribuindo com a transformação do poder judiciário sem prejudicar o atendimento territorial da população mais pobre e habitante das áreas menos acessíveis das comunidades: os oficiais de justiça. De acordo com cada legislação, esse sujeito processual pode ser ocupante de um cargo ou função judiciária (cada vez mais, reservada à bacharéis em direito, haja vista a complexidade inerente aos atos que lhes são atribuídos), e, por excelência, se trata de um agente público que torna o estado presente no território legalmente definido (Raffestin, 1993), de modo a buscar preservar a ordem legal sobre outras formas de dominação daquele (como a interação do crime ou outras formas de autotutela).

$\mathrm{Na}$ tônica das transformações dos cargos e funções no século XXI, o presente trabalho adotou como objetivo descrever as possíveis funções e perspectivas a serem assumidas pelos oficiais de justiça no seio das sociedades 4.0. A relevância deste trabalho nasceu, primeiramente, da necessidade de transformação do poder judiciário e da própria lógica inerente a suas funções, que devem se adaptar à realidade das sociedades atuais, o que, por conseguinte, repercute em transformações nas próprias carreiras e especializações especificamente exigidas dos servidores públicos e dos seus respectivos quadros.

Em segundo lugar, deve-se compreender que nenhum outro sujeito processual imparcial (especialmente, os assistentes da justiça) detém conhecimentos territoriais e uma proximidade da população, sobretudo, a parcela alijada do acesso à tecnologia e ao mercado formal, do que os oficiais de justiça. Sua participação na gestão judiciária, portanto, pode ser a chave para a compreensão das necessidades específicas daquela parcela populacional, no que toca à produção de dados para a produção de políticas públicas sobre as necessidades de prestação de justiça em cada área específica (ou, uma espécie de business intelligence judicial). E, finalmente, do ponto de vista da impossibilidade de integração do todo populacional à nova realidade de conexões e virtualidades, os oficiais de justiça ainda podem representar a chave para garantia do acesso à justiça de milhares de cidadãos.

Ainda, deve-se consignar que o presente estudo nasceu de discussões e elaborações firmadas junto ao grupo independente de estudos $O$ direito do amanhã, cuja mentoria é realizada pelos autores, com a colaboração do Érgane Instituto Científico da Amazônia, e, do CROM - Ciência a serviço da gestão pública.

Contudo, isso ainda impende de uma transformação de sua função, de modo a readequá-la e ressignificá-la às novas demandas do século XXI, o que se propõe nas linhas seguintes. Para tanto, o estudo se dividiu, além desta introdução: a) numa seção referencial, contendo os conceitos e definições tratados na análise; b) uma seção metodológica, que explicou o método e técnicas empregados; c) uma seção de resultados, cuja exposição seguiu a proposta metodológica e objetivo acima traçado; e, finalmente, d) as considerações finais.

\section{Referencial Teórico}

\subsection{A sociedade 4.0 e os oficiais de justiça do século XX}

Mata et al (2018, p. 02) compreendem por sociedade 4.0 aquela em que o relacionamento intersubjetivo se estabelece “[...] em rede que aproveita da infovia global, telecomunicações, cultura da virtualidade e quebra dos modelos de tempo e espaço físico para que indivíduos estejam aptos para realizar múltiplas tarefas".

Como, desde a primeira revolução industrial havida no século XVIII, tornou-se cada vez mais difícil dissociar os avanços decorrentes dos modelos de produção industrial e consumo capitalista das práticas sociais comuns, que se aproveita dos novos produtos e tecnologias em seu dia a dia, de outro lado, tem-se que a própria sociedade passou a ter diversas de suas práticas condicionadas pelas lógicas do mercado e metodologias propugnadas pelos produtos (Bauman, 2001).

Com isso, é natural que a sociedade deste início de século XXI conviva como novas técnicas como a internet das coisas, o big data e, mais recentemente, com a robótica e wearables. Mais adiante, certamente, a sociedade incorporará elementos 
como a realidade aumentada, a inteligência artificial, a impressão 3d, dentre outros, no âmbito do dia a dia comum (Mata $e t$ al, 2018). E, certamente, essas novas tecnologias, mesmo que de forma as vezes não tão perceptíveis, passam a modificar e condicionar a realização de práticas corriqueiras, como o trabalho, as relações familiares, a alimentação, a interação social, dentre outros.

Tornam-se, assim, cada vez mais comuns negócios jurídicos como: contratos digitais (Peck et al, 2019), as novas relações de trabalho e de ensino à distância, mediadas por Tecnologias da Informação e Comunicação (TIC's), propagandas e ofertas baseadas em comportamentos na rede ou em dados gerados pelos consumidores, economias virtuais ou virais, relacionamentos afetivos (namoros e até relacionamentos complexos de natureza familiar), ou meramente sexuais, mediados pelos ambientes virtuais etc. (Peck \& Rocha, 2018). Igualmente, surgem inúmeros problemas juridicamente relevantes à ordem social: fake news, como mecanismo de alienação coletiva, violações das mais diversas aos direitos de privacidade, inimagináveis espécies de crimes cibernéticos como os estupros virtuais, pornografia de vingança, sextortion, e vários outros ainda estudados em termos de tipicidade (Peck \& Rocha, 2018; Goodman, 2015).

Além disso, o patrimônio adquiriu uma característica relativamente imaterial ou virtualizada (sobretudo, considerandose que todo o dinheiro impresso existente nos estados, materialmente, não tem capacidade de corresponder ao quantum de moeda virtual, existente nos sistemas financeiros). Surge o dinheiro constante de ativos ou contas de criptomoedas - enquanto novas formas de ativo patrimonial - (Peck \& Rocha, 2018), e, até os chamados NFT's (non-fungible tokens - ou seja, os tokens não fungíveis), certificações digitais com registros criptográficos em blockchain (cadeias de difícil alteração registral on line) que tornam imagens como obras de arte virtuais ou meme's, vídeos ou objetos semelhantes, bens únicos (não fungíveis), portanto, apropriáveis e alienáveis (alguns, por altíssimos valores) (Techtudo, 2021).

Esse, portanto, é o contexto das sociedades 4.0, diante das quais surge "um novo salto tecnológico que tem em sua base a microeletrônica associada à informação apropriada por grandes corporações, grupos e indivíduos privados [...]", que, por sua vez, faz nascer novos conflitos sociais e práticas de apropriação de valores sociais que gera "[...] a crise estrutural do emprego" (Frigotto \& Santos, 2019, p. 41). Nesse sentido Frigotto e Santos (2019, p. 41) afirmam que "[...] a ciência e a tecnologia, desde a primeira 'Revolução' industrial foram se constituindo na força produtiva fundamental na reprodução do capital', de modo que não se tornaram acessíveis, de fato ao cidadão e às sociedades e permitindo uma distribuição desigual de recursos.

Uma revolução mais igualitária portanto, exigiria uma acessibilidade pública aos recursos tecnológicos e benesses decorrentes da evolução informacional registrada neste início de Século XXI, balanceando "[...] questões sociais que precisam ser resolvidas para garantir o desenvolvimento econômico [...]", assim como, a implantação de políticas públicas capazes de gerar “[...] o crescimento econômico [...], fornecendo bens, produtos e serviços necessários ao cidadão, independentemente da idade, gênero, região e idioma, por exemplo" (Fontanela et al, 2020, p. 41).

A construção de uma sociedade mais igualitária, em tempos tecnológicos e informacionais, impenderia, assim, de um avanço no sentido de permitir uma distribuição social dos recursos do novo tempo em prol do interesse público, materializando o que alguns autores nominam como sociedade 5.0 (Fontanela et al, 2020). Porém, como visto ao norte, esse processo dependeria, também, de uma ressignificação do papel dos estados-nação em tempos de crise, num movimento totalmente contrário à postura de diminuição do papel estatal e enfraquecimento de suas carreiras e capacidades de assistência e previdência (que, em novos tempos, poderiam assumir perspectivas igualmente voltadas à inclusão digital e tecnológica).

Essa ressignificação estatal, por sua vez, deve (ou, ao menos, deveria) levar em conta as novas oportunidades oferecias pelas tecnologias da informação e comunicação (TIC's), sem, de outro lado, ignorar a parcela territorial não coberta pelos serviços e a significativa massa populacional totalmente alijada deste processo, de modo a se utilizar, por exemplo, dos avanços inerentes ao big data, mas sem olvidar a elaboração de meios de compreensão e atingimento das comunidades mais pobres e alheias ao processo tecnológico em suas ações. 
Como mencionado anteriormente, isso se aplica sem dúvidas ao poder judiciário, que, sob a função de pacificador social e, atualmente, abarrotado pela quantidade de conflitos judicializados e resistidos sob argumentos nem sempre fundados, se vê sob o desafio de buscar novas formas de instrumentalização de suas funções e prestação da justiça às sociedades. É inegável que o poder judiciário deve acompanhar, enquanto poder responsável pela elaboração de normas jurídicas individualizadas provenientes dos julgados casuísticos, soluções adequadas aos novos tempos, sob o pálio da ideia de devido processo legal.

Porém, ainda sob o guia deste direito fundamental, cabe-lhe também a compreensão de que deve atingir de maneira isonômica os cidadãos desiguais, na exata medida de sua desigualdade, que, como discutido, as vezes compreende uma realidade separada por um abismo tecnológico ou de condições materiais (como, por exemplo, numa relação de consumo onde um consumidor, de um lado, com poucas condições e um celular adquirido unicamente por conta da realidade da pandemia - a duras custas - vê-se obrigado a lidar com a inteligência artificial de um prestador de serviços nem sempre comprometido com a clareza das condições de sua atuação).

Mais ainda, cabe ao poder judiciário ser acessivel ao cidadão, o que, de outro lado, importa também ser alcançável materialmente, ou, tornar-se territorialmente disponível ao mesmo. Explique-se: enquanto as sedes judiciárias costumam seguir a lógica das centralidades (instalando-se em regiões centrais das cidades), os problemas sociais, em sua diversidade e complexidade, podem se situar em qualquer ponto do espaço, ignorando a lógica oficial em seu comportamento e extensão. Cabe ao judiciário, de outro lado, chegar ao cidadão de maneira mais eficiente, materializando um efetivo acesso à justiça.

Nesse sentido, destaca-se o papel da atual função dos oficiais de justiça, que, enquanto agentes públicos normalmente caracterizados como servidores ocupantes de um cargo (cabe observar que nalguns estados há somente a função de oficial de justiça, atribuída, as vezes precariamente e sem maior segurança jurídica à outros cargos), atuam conforme competências estabelecidas em lei, no sentido de buscar a satisfação do interesse público, especificamente, em relação ao auxílio na prestação da atividade jurisdicional (afinal, são classificados como auxiliares da justiça) (Brasil, 2015).

Suas funções, inicialmente, são tratadas pelo código de processo civil brasileiro, de maneira não exaustiva, no teor do art. 154, que assim estabelece:

Art. 154. Incumbe ao oficial de justiça:

I - fazer pessoalmente citações, prisões, penhoras, arrestos e demais diligências próprias do seu ofício, sempre que possível na presença de 2 (duas) testemunhas, certificando no mandado o ocorrido, com menção ao lugar, ao dia e à hora;

II - executar as ordens do juiz a que estiver subordinado;

III - entregar o mandado em cartório após seu cumprimento;

IV - auxiliar o juiz na manutenção da ordem;

$\mathrm{V}$ - efetuar avaliações, quando for o caso;

VI - certificar, em mandado, proposta de autocomposição apresentada por qualquer das partes, na ocasião de realização de ato de comunicação que the couber.

Parágrafo único. Certificada a proposta de autocomposição prevista no inciso VI, o juiz ordenará a intimação da parte contrária para manifestar-se, no prazo de 5 (cinco) dias, sem prejuízo do andamento regular do processo, entendendo-se o silêncio como recusa (Brasil, 2015, não paginado).

Quanto ao cumprimento de ordens judiciais (inciso II), compreenda-se a realização de diversas atividades que variam desde a realização de leilões (na qualidade de avaliadores de bens - inciso V), como é comum ocorrer no Estado do Pará, por exemplo, a até mesmo funções de constrição (como a penhora, o arresto e o sequestro) e expropriação material de bens (como a apreensão ou adjudicação compulsória). Nesse sentido, ainda em referência ao Estado do Pará, pode-se destacar o teor da lei 6.969/2007, que especifica mais atribuições correlatas à função:

1) fazer citações, intimações, prisões, penhores (SIC), arrestos, sequestro (SIC) e demais diligências próprias do ofício e ordenadas pelo Juiz, lavrando de tudo os competentes autos, termos e certidões, sempre que possível na presença de duas testemunhas; 
2) convocar ou intimar pessoas idôneas que os auxiliem nas diligências ou testemunhem os atos de seu ofício;

3) autenticar as citações e notificações que fizerem, com a declaração da parte de ficar

"ciente" à margem do mandado ou da petição, ou com duas testemunhas, que assinem a certidão, em caso de recusa do citado, ou de não poder assinar;

4) zelar pelo prestígio da justiça, por suas prerrogativas e pela dignidade de suas funções;

5) obedecer aos prazos processuais;

6) prestar esclarecimento, por certidão, quando solicitado pelo Juiz;

7) funcionar como peritos oficiais, para o fim de determinar o valor dos bens, rendimentos, direitos e ações, descrevendo cada coisa com a precisa indicação e dando-lhe, individualmente, o respectivo valor;

8) identificar-se em suas manifestações funcionais;

9) funcionar, nos processos de competência do Juízo Privativo da Fazendas Estadual e Municipal;

10) cumprir outras determinações ordenadas pelos magistrados a que estiverem subordinados;

11) participar de treinamentos diversos de interesse da administração;

12) executar outras tarefas atinentes à categoria que lhes forem atribuídas;

13) executar as suas atividades de forma de forma integrada e cooperativa com as demais unidades do Tribunal de Justiça colaborando para o desenvolvimento dos grupos de trabalho;

14) desempenhar outras atividades correlatas ou outras atribuições que possam vir a surgir, da mesma natureza e nível de complexidade conforme as necessidades da área ou do Tribunal (Estado do Pará, 2007, não paginado).

Novamente, trata-se de um rol não exaustivo de funções que, como principal conteúdo, denota que a categoria exerce uma função predominantemente externa aos muros do judiciário, materializando, em termos práticos, o poder de coertio (coerção, ou seja, de atuação prática de sanções legalmente previstas para o cumprimento de ordens judiciais), executio (execução, ou seja, a atuação de sanções legalmente previstas, no sentido de gerar constrições para cumprimento de obrigações estabelecidas por lei) e vocatio (materializando, na prática, o poder de convocação, por intermédio das conduções coercitivas, por exemplo) inerentes ao poder jurisdicional do estado democrático de direito (Coelho, 2004). Além disso, manifestam uma atividade diretamente influente na liquidação de valores e avaliação de bens, fundamentais para a cognitio estatal (ou seja, cognição, necessária à prolação das decisões e materialização das normas jurídicas individualizadas) (Coelho, 2004), afora todo um conjunto de informações que, por meio de suas certidões, podem ser levadas ao poder judiciário, influenciando os julgamentos de conflitos.

Em verdade, de uma análise histórica da função dos oficiais de justiça, tem-se que os mesmos advém da figura jurídica colonial dos meirinhos, cargo responsável pela execução das ordens proferidas pelos meirinhos-mor (hoje, correspondentes ao que seriam os magistrados), nomenclatura extinta com o advento da constituição de 1824 (Imperio do Brazil, 1824), que assim instituiu a categoria dos officiaes de justiça.

Tem-se que, desde o período do Brasil colonial e imperial, a função detinha nítidos poderes de constrição e coerção judicial, que, ao contrário de que ocorre em outros países que optaram pela privatização da atividade (com graves limitações a sua execução), deixou a cargo de agentes públicos do império o poder de execução direta de ordens judiciais, inclusive, com autorização para porte de armas, prisão em flagrante, arrombamentos, administração do cárcere, entre outras competências, o que, tornava possível a indicação da função inclusive entre policiais (Imperio do Brazil, 1885).

A função, portanto, sempre carregou um forte aspecto ligado à própria ideia de segurança pública, como uma espécie de força policial judiciária, que, posteriormente, foi progressivamente perdendo competências para as policiais civis e militares, sobretudo, nos períodos em que o judiciário passou por limitações políticas (notadamente, no período após 1964). Porém, ainda assim, é importante observar que o embrião dessa função sempre a revelou como um conjunto de atribuições que permitem a tomada de medidas coercitivas e constritivas, núcleo fundante que, por sua vez, tem sido levado em conta em projetos de lei que buscam sua transformação e, como se verá mais adiante, podem inspirar os futuros contornos dos oficiais de justiça de uma sociedade 4.0, ou, até mesmo, 5.0. Para tanto, é necessário readequar os elementos constritivos e coercitivos em questão, primeiramente, ao espírito democrático da atual constituição, e, em seguida, às novas possibilidades inerentes ao desenvolvimento tecnológico atual. 
Para além, é importante verificar que o protagonismo judicial, como discutido acima, impõe uma postura mais ativa, no sentido de compreender a sociedade em que deve prestar justiça, o que, mais uma vez, pode atribuir novas funções estratégicas à figura dos oficiais, conforme se discutirá adiante, no tópico de resultados.

\section{Metodologia}

Primeiramente, a pesquisa partiu do método indutivo, assim compreendido por Bittar (2016), como o percurso metodológico que colhe evidências particulares eventualmente generalizáveis. Buscou, assim, a compreensão de elementos constantes de projetos de lei (PL's) e propostas isoladamente existentes em cada estado, para, numa generalização, sugerir mudanças de caráter nacional quanto à atribuição dos oficiais de justiça. É claro que, neste processo de generalização, o estudo realizou uma atividade igualmente intuitiva (Bittar, 2016), decorrente da interpretação das atuais propostas relativas à função dos oficiais de justiça, das normas jurídicas constritivas e coercitivas atualmente existentes, para vislumbrar suas potenciais transformações futuras, e, de que forma estas se correlacionariam com a categoria em estudo.

Por conseguinte, como técnica de levantamento, o estudo se valeu de uma pesquisa documental, pautada em projetos de lei estaduais e federais relativos à propositura de novas atribuições ou transformações das atribuições atualmente existentes em relação ao cargo dos oficiais de justiça. Em seguida, os documentos foram organizados e sujeitos a um processo de análise de conteúdo (Bardin, 2011), para fins de exposição organizada no tópico de resultados, o qual, por conseguinte, passou a ser objeto de conjecturas em relação ao futuro.

Ademais, o estudo levantou as possíveis tecnologias constritivas e coercitivas igualmente propostas para o futuro do direito, verificando a possibilidade de diálogo entre as mesmas e as atribuições inerentes aos oficiais de justiça. Os resultados, ademais, se encontram expostos na seção subsequente.

\section{Resultados: os oficiais de justiça e a sociedade 4.0}

\subsection{As propostas de novas atribuições e prerrogativas funcionais}

Primeiramente, constatou-se a existência de projetos de lei prevendo a inclusão da categoria dos oficiais de justiça dentre as autorizadas a deter porte de arma de fogo e aquisição de armamentos e munições especiais. Nesse sentido, sob proposições semelhantes, verificou-se a existência do PL n. 5415/2005, PL n. 3722/2012 e do PL n. 6438/2020, na Câmara dos Deputados (Brasil, 2005, 2012, 2020b), bem como, do PL n. 2525/2019 e do PL n. 3713/2019, no Senado Federal (Brasil, 2019b, 2019c).

A rigor, se trata de um revolvimento de prerrogativas historicamente garantidas aos oficiais de justiça, dada a natural externalidade de suas funções e os riscos que, por sua vez, acabam surgimento no cotidiano de trabalho. Afinal, tratam-se de agentes estatais que, ao buscar a imposição de decisões judiciais, certamente, acabam vivenciando momentos de antagonismo com os interesses de outros agentes territoriais públicos ou privados, o que, por sua vez, pode desembocar em inevitáveis conflitos. Nesse sentido, tem-se que Simões et al (2021) identificou que os oficiais de justiça, seja em áreas urbanas, seja em áreas rurais, vivenciam diversos riscos funcionais variados, com destaque especial para a violência, que, sobrevém aos mesmos de maneiras imprevisíveis e, aos poucos, é internalizada, com graves riscos à saúde.

De fato, se acompanhado de um devido treinamento (a ser periodicamente renovado) a medida pode surtir efeitos positivos em relação às ameaças naturalmente impostas ao exercício funcional da categoria, o que, de outro lado, não exclui o risco de outros crimes, como os roubos voltados à obtenção de armas ou as ameaças diretas protagonizadas por organizações como as atuais facções criminosas, cujas ações de enfrentamento e oposição ao Estado de direito se tornaram comuns nas últimas décadas (Reis Netto \& Chagas, 2019). 
Por sua vez, ainda visando a segurança do exercício funcional, restaram identificados projetos de lei atinentes à livre parada de veículos na via pública, para fins de cumprimento de ordens judiciais. Nesse sentido, verificou-se o PL n. 9719/2018 e o PL n. 1608/2019 (Brasil, 2018, 2019a), ambos, oriundos da Câmara dos Deputados. Novamente, a tônica reside na atribuição de prerrogativas voltadas à segurança dos oficiais, que, com a livre parada, teriam uma maior proximidade entre o veículo usado para cumprimento da ordem (na maioria dos casos, um veículo pessoal) (Simões et al, 2021), bem como, uma maior possibilidade de fuga ou abrigamento em situações de risco, além da eliminação de custos com estacionamentos ou semelhantes, comuns nas áreas urbanas das capitais.

Contudo, as propostas mais significativas estão conglobadas no teor do PL n. 4755/2020 e do PL n. 1117/2021 (Brasil, 2020a, 2021a), que pretendem alterações no teor do Código de Processo Penal Brasileiro - O Decreto-lei N. 3.689/1941 (Brasil, 1941). Além de alterações relativas à ampliação da participação dos oficiais na produção probatória criminal, o que de fato, é uma função que já é realizada por muitos oficiais de justiça na prática (por meio de vistorias sobre imóveis, exames sobre pessoas e coisas, apreensão de documentos, descrições, dentre outros), os PL's propõem a ascensão dos oficiais de justiça ao status de função típica de estado e como agentes de inteligência. A caracterização dos oficiais enquanto função típica de estado, aliás. diz respeito a uma forma de resistência da categoria num contexto político frágil, atualmente vivido no país.

A proposta se coloca como uma forma de impor a real importância dos oficiais, diante de uma reforma administrativa que propõe a precarização e instabilidade de diversos agentes públicos, inclusive concursados, lançando-os a um contexto de variações salariais e de carga horária incertos, e, sobretudo, que pode ocasionar uma ampla politização do processo de ingresso em diversas funções, o que, conforme comprovam Reis Netto et al (2019), em muito redunda no surgimento de casos de corrupção e não adesão a propósitos institucionais. Caracterizá-los como tal, impediria o atingimento da categoria pelos sombrios ventos da reforma em questão, uma vez que os afastaria das precarizações propostas pelo projeto (que, atualmente, isenta somente membros da magistratura, ministério público, e, com restrições, as defensorias e polícias). No entanto, como crítica, deve-se dizer que há outros projetos relativos à criação de funções típicas de estado que se direcionam à constituição ou normas específicas aos cargos concorrentes, o que, por sua vez, torna questionável a tentativa de ascensão da categoria pela via do código de processo penal, e, assim, pode representar uma fragilidade para o sucesso da proposição.

Outro ponto que fragiliza o intento do projeto de lei, igualmente, diz respeito às tentativas de desjudicialização das ações de execução civil, objeto de outros PL's em tramitação. Por intermédio destes, a competência para realização de diversos atos executivos seria atribuída aos atuais cartórios. Obviamente, o perigo dessa proposta reside nos atuais problemas de fiscalização dessas entidades privadas, cujos problemas históricos de controle e corrupção são mais que conhecidos, além de uma série de outros problemas relativos à ausência de mecanismos de garantia de uma igualdade processual e ao acesso à justiça, destacados por Reis Netto e Miranda (2021).

Por conseguinte, o enquadramento dos oficiais de justiça enquanto agentes de inteligência, diz respeito à possibilidade da categoria atuar no levantamento de um conjunto de informações relevantes à prática judiciária, muito embora, o conceito utilizado no projeto não tenha sido o mais apropriado (ao mencionar somente inteligência, ao invés de inteligência judiciária). Explique-se: a chamada atividade de inteligência diz respeito uma função estatal específica, que se utiliza de metodologias próprias (que beiram à ilegalidade em muitos aspectos) para levantamento de informações secretas ou abertas de qualquer atividade potencialmente perigosa ao Estado e/ou interesse público (Cepik, 2003). Ou seja, trata-se de uma função invasiva às liberdades individuais, sob diversas perspectivas, no sentido de obter informações capazes de assessorar processos decisórios relativos à ações do estado, conforme propósitos específicos das gestões, para um menor gasto de recursos e energia na realização de planos políticos em áreas estratégias (Raffestin, 1993), sobretudo, defesa e segurança pública. 
Aceitar a atuação dos oficiais dentro da chamada atividade de inteligência, propriamente dita, geraria uma série de problemas práticos aparentemente não estudados ou vislumbrados quando da proposição legislativa: a) a prática de inteligência, a rigor, só pode ser praticada por agentes e entidades vinculadas ao Sistema Brasileiro de Inteligência - o SISBIN, instituído pela lei n. 9.883/1999 (Brasil, 1999); b) Embora possível, só se aceitaria a prática de atividades vinculadas à inteligência, eventualmente e sob total sigilo, por sujeitos externos àquela comunidade, na qualidade de agentes colaboradores, sem muitas seguranças jurídicas e sem remuneração direta ou incorporável; c) A prática de atos de inteligência por pessoas sem competência especificamente prevista para tal (o que pressupõe treinamento, formações específicas, dentre outros), poderia importar na nulidade jurídica dos atos praticados, em razão do critério competência e finalidade inerente aos atos administrativos vinculados à atividade de inteligência (Nascimento et al, 2018; Reis Netto et al, 2018).

No entanto, como já mencionado anteriormente, a função do oficial de justiça pode ser estratégica quanto ao levantamento de uma série de dados e informações essenciais à prestação da função jurisdicional pelo Estado, sobretudo, para produção de conhecimentos relativos à parcela populacional e territorial excluída do mundo virtual e não (seletivamente) englobada pelo mundo do big data. Contudo, isso se referiria a uma espécie de inteligência judiciária, muito mais vinculada à ideia de business intelligence (B.I.), ou inteligência de negócios, que ajudaria o poder judiciário na obtenção de conhecimentos mais propícios a prestação de seu serviço público por primazia: a justiça. Note-se: essa função é diferente até mesmo da segurança de magistrados, vinculada a setores impropriamente nominados como inteligência, de determinados tribunais de justiça (como o TJPA), que levanta informações sobre a segurança dos agentes públicos que atuam na área criminal, sem, no entanto, fazer parte direta e oficialmente da comunidade de inteligência, se valendo da atuação de policiais e bombeiros militares para tal fim.

No caso, a mudança da nomenclatura seria necessária à própria aceitação da propositura legislativa, sendo apropriado que se adapte, no teor da exposição de motivos do projeto, uma correta explanação sobre o alcance da atividade de $B$. $I$. que poderia ser desenvolvida (de maneira muito interessante) pela categoria, sobretudo, quanto ao mapeamento de áreas, levantamento de características populacionais ou de zonas de tensão territorial, dentre outros. Caso contrário, o projeto pode se ver atingido por vícios de constitucionalidade.

\subsection{Outras propostas locais}

Para além dos projetos de lei acima, tem-se que, em cada estado, os cargos/funções de oficiais de justiça passam por algumas proposições interessantes. Sobretudo no estado do Pará, donde advém algumas das principais lideranças sindicais da categoria, tem-se que surgem propostas como a dos oficiais de justiça pacificadores, que reforçam o emprego de técnicas de conciliação e mediação (por metodologias diversas) para reforço da possibilidade de atuação dos profissionais na resolução de conflitos (Lima Junior, 2019). De fato, uma atuação mais conformada aos princípios da não-litigância e da cooperação processual, além de se conformarem às normas processuais que regem a atividade dos oficiais, certamente, representa uma maior adequação da categoria aos novos rumos do processo civil relacional.

No Pará, igualmente, em razão do contexto da pandemia de COVID-19, viu-se o advento, por iniciativa do próprio Tribunal de Justiça do Estado do Pará, do uso de aplicativos de comunicação instantânea para a realização de atos processuais. Certamente, trata-se de uma medida que impõe uma maior celeridade à prática de muitos atos processuais e atualmente é aceita como válida em pronunciamentos do Superior Tribunal de Justiça:

Como cediço, a tecnologia em questão permite a troca de arquivos de texto e de imagens, o que possibilita ao oficial de justiça, com quase igual precisão da verificação pessoal, aferir a autenticidade da conversa. É possível imaginar-se, por exemplo, a exigência pelo agente público do envio de foto do documento de identificação do acusado, de um termo de ciência do ato citatório assinado de próprio punho, quando o oficial possuir algum documento do citando para poder comparar as assinaturas, ou qualquer outra medida que torne inconteste tratar-se de conversa travada com 
o verdadeiro denunciado. De outro lado, a mera confirmação escrita da identidade pelo citando não nos parece suficiente. [...] Necessário distinguir, porém, essa situação daquela em que, além da escrita pelo citando, há no aplicativo foto individual dele. Nesse caso, ante a mitigação dos riscos, diante da concorrência de três elementos indutivos da autenticidade do destinatário, número de telefone, confirmação escrita e foto individual, entendo possível presumir-se que a citação se deu de maneira válida, ressalvado o direito do citando de, posteriormente, comprovar eventual nulidade, seja com registro de ocorrência de furto, roubo ou perda do celular na época da citação, com contrato de permuta, com testemunhas ou qualquer outro meio válido que autorize concluir de forma assertiva não ter havido citação válida (Brasil, 2021b).

Além disso, pode-se identificar iniciativas isoladas de diversos oficiais, em busca da inovação em sua função. Como exemplo, cita-se a elaboração do primeiro autor do presente estudo, que com o auxílio do grupo de estudos mencionado ao início do presente escrito, passou a aplicar competências e habilidades atualmente debatidas em disciplinas como direito digital, design thinking (design aplicado ao conhecimento de diversas áreas), visual law (direito visual) e legal design (design aplicado ao direito), para sua atuação profissional individual. Após entrevistas com servidores, magistrados e outros oficiais de justiça, buscou-se uma mudança do modelo tradicional de certificação de mandados, buscando uma maior objetividade das informações e a utilização de elementos gráficos que facilitassem uma rápida identificação de informações relevantes e do resultado da diligência de cumprimento de mandados judiciais (Figura 1).

A prototipagem deste modelo documental, atualmente, se encontra numa segunda etapa, na qual os pesquisadores estão testando aplicativos comuns, que poderiam ser instalados e utilizados sem maiores dificuldades em celulares pessoais, por intermédio dos quais se poderia gerar um $Q R$ code (quick response code - código de resposta rápida), que pudesse indicar as coordenadas dos locais de cumprimentos de ordens judiciais, que, por sua vez, seriam diretamente copiáveis pelos serventuários de varas e secretarias em mandados futuros, facilitando o deslocamento do mesmo ou de outros oficiais, para cumprimento de outras ordens no mesmo local (Figura 2). 
Figura 1 - Modelo de certidão, elaborado sob princípios do design thinking, visual law e legal design, aplicado pelo primeiro autor do estudo em sua praxe profissional, criado após entrevistas e verificação de necessidades e formas mais objetivas de consignação de informações.

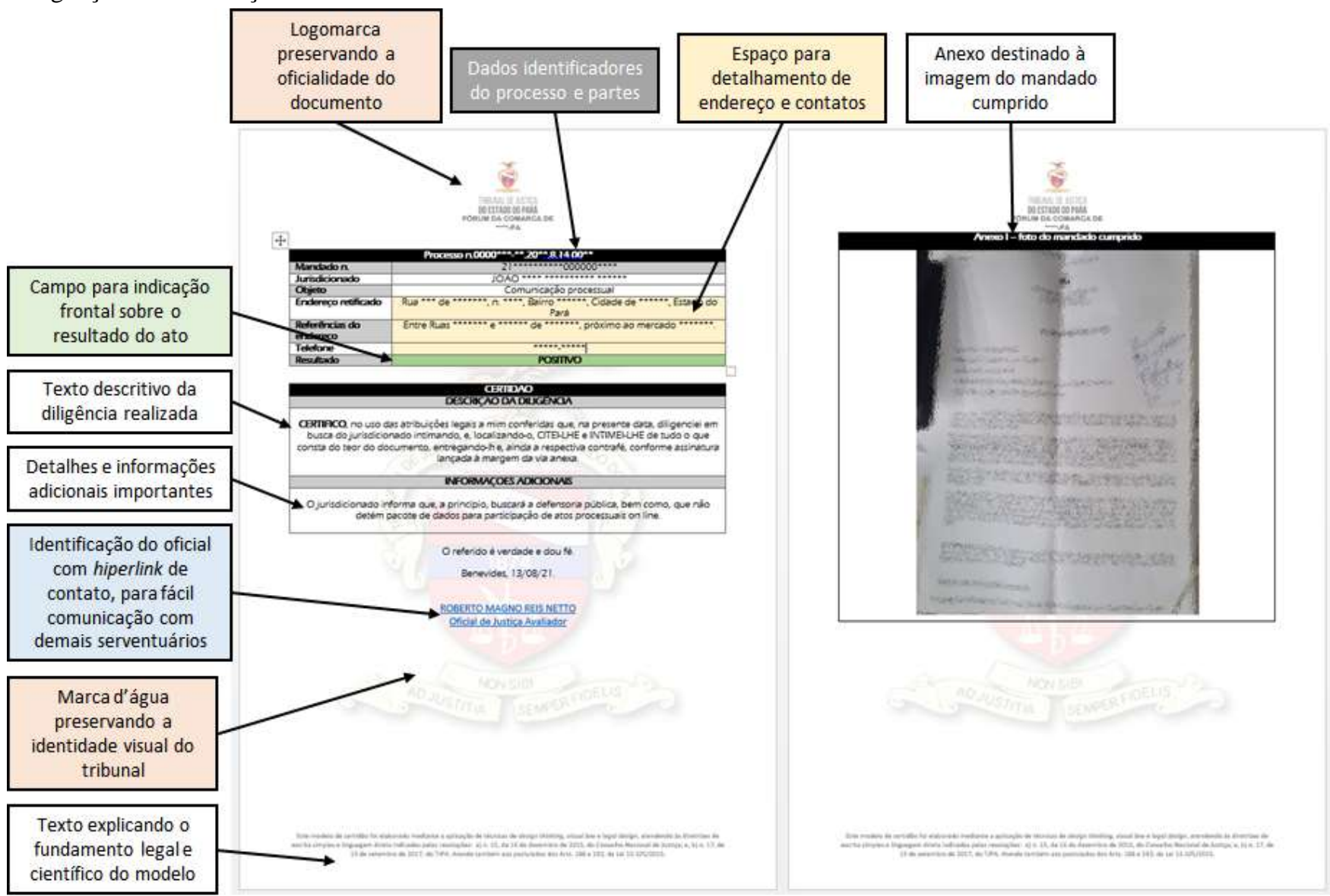

Fonte: a) Modelo de certidão: elaboração do primeiro autor do estudo, pertencente ao acervo pessoal do mesmo (com informações suprimidas em respeito às partes processuais envolvidas); b) Imagem, com informações: elaboração dos autores.

Obs.: O texto explicativo dos fundamentos legais e científicos do modelo acima, consigna a seguinte informação: "Este modelo de certidão foi elaborado mediante a aplicação de técnicas de design thinking, visual law e legal design, atendendo às diretrizes de escrita simples e linguagem direta indicadas pelas resoluções: a) n. 15, de 16 de dezembro de 2015, do Conselho Nacional de Justiça; e, b) n. 17 , de 13 de setembro de 2017, do TJPA. Atende também aos postulados dos Arts. 188 e 192, da Lei 13.105/2015”.

Figura 2 - Exemplo de coordenada extraída a partir da localização do Fórum da Comarca de Benevides-PA (ponto em vermelho), que, submetido à aplicativo específico, ocasionou a geração de $Q R$ Code para acesso à coordenada do local indicado.
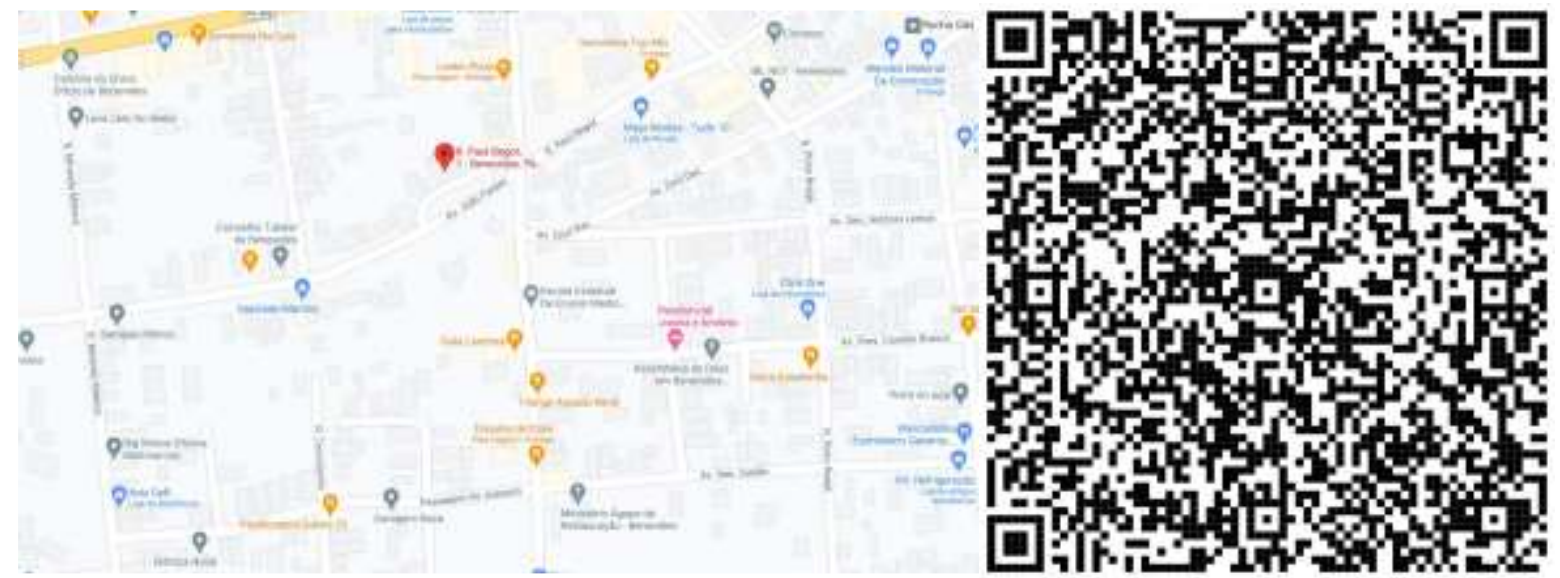

Fonte: a) Imagem do mapa: elaborada pelos autores a partir do Google Earth (2021); b) $Q R$ Code: elaborado pelos autores a partir da ferramenta $Q R$ Code generator (2021).

OBS: A coordenada pode ser livremente testada pelo celular do leitor, ressalte-se. 
Obviamente, os autores ainda enfrentam o problema relativo à inexistência de ferramenta gratuita que sirva à navegação, pontuação em mapas e geração automática ou posterior de $Q R$ Codes utilizáveis, conforme o propósito assinalado. Além disso, a viabilidade da medida dependeria, certamente, da elaboração de um aplicativo específico pelo setor de tecnologia dos tribunais, o que, por sua vez, também depende da concordância dos gestores.

Ainda assim, a ferramenta, se de fato acessível, seria utilizada pelo próprio celular pessoal dos oficiais de justiça (pela mesma lógica do BYOD - bring your own device, ou, traga seu próprio dispositivo ao local de trabalho, numa prática que, aliás, naturalmente já ocorre em todo Brasil, uma vez que os oficiais trabalham usando uma série de recursos próprios, como seus aparelhos celulares e seus próprios veículos). Certamente, a medida tornaria mais fácil a localização de diversos jurisdicionados e, com isso, geraria uma maior celeridade processual, economia dos recursos pessoais dos oficiais utilizados no cumprimento de ordens (que, não é compensado ou indenizado em muitos estados, ressalte-se), e, mais ainda, diminuiria a ocorrência de erros pelas secretarias (que, em ocasiões não raras, impõe um deslocamento desnecessário de oficiais por quilômetros de distância, sem sucesso). Isso, sem contar a eliminação de riscos pela redução do tempo de exposição na rua.

Em suma, pode-se observar que há diversas outras possibilidades de surgimento de novos rumos e possibilidades profissionais aos oficiais. Porém, para além disso, compreende-se a necessidade de uma transformação mais intensa da categoria no sentido de realmente liga-la às necessidades do século XXI. É sobre essas reflexões, que se ocupou o próximo tópico.

\subsection{Volver ao passado para enxergar o amanhã}

Como dito, tem-se que a função jurisdicional é composta por atributos cognitivos de fatos e situações (notio) para que os magistrados possam proferir decisões judiciais (judicium), e, elementos tipicamente sancionadores, ou seja, que aplicam sanções (constrangimentos, coerções) legais para garantia de obediência às ordens judiciais: vocatio (poder de convocação perante o juízo, se necessário, à força), coertio (poder de coerção, ou ameaça de aplicação de penalidades legalmente previstas) e executio (a aplicação concreta de medidas constritivas patrimoniais ou pessoais, estas, mais presentes na esfera penal, em decorrência da implementação prática de provimentos jurisdicionais ou legais) (Coelho, 2004).

E, de uma análise histórica das funções exercidas pelos oficiais de justiça, desde o período colonial, tem-se que sempre lhes foi comum o exercício de atribuições vinculadas à vocatio (como as conduções coercitivas, buscas e apreensões de menores para fins de depoimento especial ou acolhimento, por exemplo), coertio (na apreensão de coisas, aplicações de ordens de restrição de direitos, como os lacres, etc.) e, principalmente, executio (sobretudo, na constrição e expropriação de bens, como nas penhoras e adjudicações, por exemplo). Contudo, tem-se que essas funções parecem ter estagnado no tempo, diante da gama de atuais possibilidades de coerção e execução, não só em decorrência de escolhas políticas legislativas que as atribuem às figuras dos magistrados (categoria que, em termos numéricos, é significativamente inferior à dos oficiais de justiça), como, sobretudo, em decorrência da reincidente incapacidade legislativa de inovação processual, comumente demonstrada pelo Poder Legislativo brasileiro, quanto às novas possibilidades do século XXI.

Nesse sentido, se, classicamente, os oficiais de justiça podem naturalmente ingressar em qualquer local para cumprimento de uma ordem judicial constritiva, penhorando a apreendendo bens e dinheiro, é inconcebível que estes poderes ainda não lhes tenham sido estendidos, também, ao mundo virtual. A penhora de ativos bancários, nesse sentido, é admitida desde o surgimento do sistema Bacenjud (sistema instituído junto ao banco central que permite o bloqueio de ativos em sistema), estando, no entanto, restrita à figura dos magistrados, que detém acessibilidade e poder de operação sobre o sistema.

Contudo, por vezes ocorre a total frustração da medida em razão do lapso de tempo necessário à prolatação da ordem judicial, acompanhada de todos os procedimentos burocráticos de efetivação prática da medida no sistema, em inúmeros processos. Uma possibilidade que aqui se concebe é que este poder seja deslocado da esfera de competência dos magistrados, 
para a dos oficiais de justiça, no sentido de que, proferida a ordem judicial de bloqueio de ativos (o que seria feito de maneira mais rápida e prática pelos magistrados), a decisão seja imediatamente distribuída na forma de decisão/mandado (possibilidade admitida no novo Código de Processo Civil, ante o princípio da instrumentalidade das formas), no próprio sistema virtual ou físico, para um dos diversos oficiais lotados em cada comarca, que poderá efetivar a medida em prazo a ser legalmente fixado por lei ou normativas dos tribunais, tornando o processo mais rápido e prático.

Afinal, se a penhora de valores é possível fisicamente, porque haveria problemas de sê-lo virtualmente? É uma possibilidade premente. Ainda mais, considerando que, cada vez mais, a movimentação de dinheiro se afasta das formas físicas privilegiando as transferências por cartões de crédito/débito e por pix. Além disso, como também dito, a sociedade caminha cada vez mais na direção de uma economia pautada em ativos virtuais, como as já mencionadas criptomoedas e os NFT's, que constituem objetos detentores de valor, portanto, potencialmente utilizáveis para reparação ou compensação do danos causados ou obrigações frustradas. Não à toa, o Conselho Nacional de Justiça já emprega significativa atenção e recursos à migração, já em conclusão e teste, para um novo sistema de bloqueio de ativos: o Sisbajud. O novo sistema prevê a possibilidade de penhora (on line) de criptomoedas, além de prometer uma maior capacidade operacional e respostas mais rápidas nas ordens de transferência e adjudicação (José, 2020).

Contudo, apesar da inovação quanto ao sistema, não se inova quanto aos operadores, os magistrados, que continuam circundados por uma infinidade de processos nos quais precisam promover medidas de diversas naturezas, o que, por sua vez, acaba relegando muitas medidas executivas (práticas), a um segundo plano, haja vista a necessidade cumprimento de metas do próprio Conselho Nacional de Justiça e da necessidade de atenção específica às constrições necessárias em cada caso.

Para além do bloqueio que ativos, o deslocamento à esfera de competências dos oficiais de justiça também poderia se dar em relação às medidas operacionalizadas por meio dos sistemas Renajud (vinculado ao Registro Nacional de Veículos Automotores) e do Sistema de Registro Eletrônico de Imóveis - SREI. Isso também representaria a mesma possibilidade de inovação e avanço acima elencada em relação ao atual Bacenjud, apesar de não se tratada por nenhum dos atuais projetos de lei.

Certamente, esse deslocamento de competências necessitaria da aprovação de lei alterando a sistemática do Código de Processo Civil (Brasil, 2015) e normativas infralegais. Além do que, tornaria necessária a exigência de que os oficiais de justiça do Brasil inteiro detivessem, ao menos, o grau de bacharel em direito, exigindo-lhes novos conhecimentos específicos no concurso de ingresso e capacitação dos oficiais já investidos. Contudo, trata-se de possibilidade que, sem dúvidas, promoveria uma maior velocidade nas medidas de constrição, justamente, pela quantidade de oficiais existentes, e pelo deslocamento de funções que ocupam demais os magistrados na atualidade. Quanto à segurança, o natural registro de senhas e controle de acessos e protocolos, certamente, tornaria a atribuição segura nas mãos de oficiais (tanto quanto na de magistrados), que, além de só cumprirem estas medidas sob ordem específica, teriam que respeitar procedimentos legais e normativos e, sobretudo, atuariam somente após capacitação e obtenção de chaves e níveis específicos de acesso.

Por conseguinte, ainda sob a sistemática dos sistema de informação, tem-se que a atribuição de níveis de acesso aos oficiais de justiça, mesmo que mínimos, em sistemas como o Infoseg (vinculado a área da Segurança Pública) e o Infopen (vinculado a área penitenciária), também seria de grande valia para aceleração do cumprimento de diversos atos processuais. Por vezes, quando do cumprimento de ordens, descobre-se que o comunicando de um ato se encontra preso, nada se sabendo informar a respeito da unidade em que se encontra, o que seria rapidamente resolúvel por uma consulta ao pertinente sistema. De igual maneira, as informações gerais a respeito dos cidadãos, permitiriam que o mesmo fosse localizado mais de forma mais fácil (lembrando que os oficiais devem efetivar os atos de comunicação processual junto aos jurisdicionados no endereço indicado no mandado, ou, onde aqueles se encontrem - Art. 251, do Código de Processo Civil) (Brasil, 2015). 
Também, tem-se que esse acesso à informações específicas, somado à possibilidade criada nalguns estados (como já citado, por exemplo, em relação ao Pará), de realização de atos processuais por intermédio de aplicativo de mensagens, ou, ainda, por e-mails, certamente, traria bastante celeridade para os processos, sobretudo, considerando o alto nível de interação que a atual sociedade mantém com redes sociais e ambientes virtuais.

Ainda, a criação de um sistema próprio de atuação para os oficiais poderia ser de grande auxílio para o sucesso dos processos. Atualmente, por mais descritivas que sejam as certidões a respeito dos endereços (muitas, até fazendo menção à coordenadas geográficas), tem-se que, pelo volume de feitos, os serventuários dos cartórios e varas acabam ignorando os detalhes de diligências anteriores, repetindo endereços de forma genérica. Isso, após certo tempo, poderá ocasionar até a frustração de posteriores comunicações processuais, sobretudo, considerando a realidade de logradouros desordenados e ocupações irregulares de muitos municípios brasileiros. Esse problema seria sanado mediante o uso de tecnologias que possibilitassem o registro dos locais de cumprimento das diligências (como já se mencionou e exemplificou pelo exemplo da geração de $Q R$ codes, acima), que ficariam vinculados aos processos e, por sua vez, poderiam também retroalimentar outros sistemas, como o Infoseg, por exemplo. É umas das possíveis atividades de um oficial com atribuições de business intelligence, cuja atuação criaria indicadores geográficos importantes à prestação jurisdicional e, até mesmo, à elaboração de políticas públicas (por exemplo, para áreas com muitas ocorrências de um tipo de crime ou tipo de violação civil de direitos).

Novamente, capacitações e a futura exigência de conhecimentos especializados seriam essenciais para o sucesso dessas novas atribuições. Porém, essa cobrança apenas reforçaria o natural grau de conhecimentos específicos exigidos para o exercício da função (realidade, por exemplo, do estado do Pará), valorizando mais ainda a função. Do mesmo modo, atribuições mais estratégicas reforçariam o pretendido caráter de carreira típica de estado, já discutido acima.

\subsection{Uma proposta mais radical: oficiais como forças de segurança judiciária}

Novamente, volvendo os olhos ao passado, tem-se que os oficiais de justiça já exerceram, sobretudo, no período colonial (quando meirinhos), funções nitidamente vinculadas à área da segurança e defesa, assim compreendida, hodiernamente, como área do conhecimento jurídico-político responsável pela identificação de vulnerabilidades e riscos sociais, na qual se busca a compreensão dos mesmos para elaboração de políticas específicas de enfrentamento (Ruditz \& Nogami, 2010). Portanto, era natural que oficiais desempenhassem atribuições ligadas, em larga medida, à segurança dos órgãos do sistema judiciário, como os fóruns, carceragens e prisões. Sua atuação, em muito, se confundia com atuais funções das polícias civis, militares e penais.

E, na atualidade, não é raro que, para além das prisões civis, os oficiais, em situações mais limítrofes, também tenham que executar prisões penais (de foragidos, por crimes de desobediência ou falso testemunho, por exemplo) ou apreensões de adolescentes, dentre outros, mesmo que estejam normalmente desguarnecidos por armamentos e equipamentos específicos, o que torna a atividade seja bem mais dificultosa, nos dias atuais. Além disso, como bem se vê do art. 154, IV, a lei dispõe como função dos oficiais de justiça "auxiliar o juiz na manutenção da ordem" (Brasil, 2015, não paginado), pelo que os mesmos são acionados em diversos atos públicos como verdadeiros garantes da ordem processual.

Para além disso, tem-se que os oficiais de justiça diariamente vivenciam uma série de riscos de diversas naturezas, quando da efetivação das ordens judiciais mais triviais que lhes sejam atribuídas, justamente, em razão dos níveis de criminalidade atualmente observados, sob variadas modalidades, nas cidades urbanas ou rurais brasileiras (Simões et al, 2021).

Inegavelmente, a função nunca se desvinculou materialmente do campo da segurança e defesa, razão pela qual, inclusive, se identificaram as propostas relativas à concessão de porte de arma aos ocupantes do cargo/função de oficial de justiça, como uma forma de tentar diminuir riscos e viabilizar a capacidade de cumprimento de medidas coercitivas mais graves. 
Ao ser-lhes atribuído o dever de garantia da segurança jurídica das relações processuais (para cuja preservação, se exige em muitas ocasiões que os agentes se valham de uma ação mais contundente), perpassando pela noção de segurança humana (uma vez que, em suas ações, devem tomar todas as medidas necessárias no sentido de preservar a integridade física e moral de muitos sujeitos, não raro, sob conflito), ao fim e ao cabo, cabe-lhes uma verdadeira garantia da segurança pública de uma série de atos que envolvam a ação do Poder Judiciário (uma vez que estes profissionais, em várias ocasiões cotidianas dos fóruns e repartições, se deparam com condutas criminosas que exigem ações cautelosas, fundamentadas e imediatas).

Nesse contexto, é de se questionar se o retorno desta categoria à qualidade de força de segurança e defesa não caracterizaria um dos possíveis caminhos de transformação (além dos vários apontados acima), no decorrer deste Século XXI?

Compreende-se como plausível uma resposta afirmativa, primeiramente, pelo fato de que a função já se encontra naturalmente inserida nas atribuições do chamado sistema judiciário penal, que inegavelmente envolve de forma direta $o$ combate à criminalidade, a custódia de pessoas em conflito com a lei e a reinserção social. Em segundo lugar, embora a função dos oficiais não seja diretamente afeta ao o combate ostensivo e repressão à ilícitos, pelo seu dever de ação e pelo contato constante com áreas inerentes à atividades ilegais (haja vista transitarem por todo território ao qual a jurisdição dos tribunais adere), é natural que tenham que entrar em contato com aquelas e, obviamente, também reprimi-las quando necessário

Diante disso, é inevitável concluir que os oficiais acabam exercendo funções limítrofes à área de segurança pública propriamente dita, sem, no entanto, gozar de uma série de prerrogativas inerentes às carreiras policiais comuns ou penitenciárias, que, certamente, lhes trariam muito mais segurança e capacidade técnica para o cumprimento de ordem mais gravosas, como as mencionadas prisões e buscas e apreensões de adolescentes em conflito com a lei, por exemplo.

De forma mais radical, tem-se que o cargo de oficial de justiça poderia ser reinserido num campo de atribuições e poderes diretamente vinculados à defesa das instalações, atividades e autoridades do Poder Judiciário, como, em larga medida (e sem devidas retribuições ou reconhecimentos) acabam fazendo em seu dia a dia.

Aliás, essa possibilidade atenderia à uma necessidade premente do Judiciário: a instituição das chamadas polícias judiciais, no âmbito de seus respectivos níveis e entidades federativas, conforme previsto em resolução específica do Conselho Nacional de Justiça, cujo intuito principal é liberar agentes de outras forças policiais (destacados para funções junto ao judiciário) permitindo seu retorno para os respectivos quadros específicos. Analisando-se as atribuições que serão desempenhadas por esta nova polícia, tem-se que a mesma compõe diversas atividades que os oficiais, na prática, já exercem impropriamente: a segurança dos órgãos e instalações do poder judiciário; a escola e proteção de magistrados (comum, sobretudo, nos interiores onde o efetivo policial é reduzido), a apreensão de bens e pessoas, segurança de audiências, dentre outras previsões da resolução n. 344/2020, do Conselho Nacional de Justiça (Brasil, 2020c).

Além disso, a transformação progressiva da carreira numa força voltada à segurança judicial, corresponderia perfeitamente aos pretendidos projetos de lei que buscam a ampliação de seus poderes executivos cíveis e penais (como visto nos itens anteriores), justificando, o pretendido porte de arma e, até mesmo, o efetivo exercício de uma atividade de inteligência, propriamente dita (para muito além das funções de business intelligence sugeridas), tornando mais que coerente, neste contexto, seu enquadramento enquanto uma função típica de estado.

Assim, a criação das inspetorias de polícia judicial poderia partir da inclusão legal de atribuições funcionais e treinamento dos próprios oficiais de justiça, em sua maioria, bacharéis em direito (portanto, qualificados para as atribuições que seriam exigidas em eventuais concursos de ingresso à polícia judicial), com o progressivo retorno da categoria à funções de segurança que, historicamente, já eram exercidas pela mesma.

Certamente, essa transformação justificaria o próprio termo oficial ostentado por estes agentes, tipicamente destinado à autoridades públicas qualificadas para o exercício de funções de comando na área da segurança e defesa, nas polícias e forças armadas. Basta, tão somente, a promoção de um pacote de alterações legislativas inerentes às atribuições do cargo, seguida da 
requalificação e treinamento de agentes e, ao fim, um reescalonamento de quantitativos. E, embora isso pareça custoso ao erário num primeiro momento, tem-se que, em verdade, ser estaria criando um verdadeiro conjunto de agentes públicos especializados em execução judicial, no sentido mais amplo da palavra.

Seria, portanto, um novo rumo totalmente inédito para a categoria, que, no entanto, surgiria como solução para uma série de questionamentos a respeito da sua (inquestionável) real necessidade ao judiciário e à sociedade. Aliás, quanto a essa última, convém lembrar que sua parcela mais humilde e desfavorecida somente é atingida e conhecida por aqueles que realizam periódicas (e corajosas) incursões territoriais nas áreas socialmente esquecidas e, muitas vezes, dominadas por poderes paralelos: os oficiais de justiça.

Admitir sua transformação numa categoria de verdadeiros oficiais de execução especializada e segurança, no sentido mais amplo da terminologia, alçará a categoria a um novo patamar impensado, de fato, porém, que talvez seja o mais adequado às transformações vivenciadas neste início de século XXI.

\section{Considerações Finais}

O presente artigo, teve como objetivo descrever as possíveis funções e perspectivas que poderiam ser assumidas pelos oficiais de justiça no seio das sociedades 4.0. E, ao final das reflexões destacadas, verificou-se que, para além das propostas legislativas e locais, atualmente existentes, que, sobretudo, buscam sua caracterização como um função típica de estado e propõem a incorporação de novas funções a sua esfera de competência, a integração dos oficiais de justiça à novas atividades (como a de inteligência judicial e de execução de novas formas de constrições patrimoniais) poderia representar a evolução desta categoria para um novo patamar útil ao judiciário e sociedade.

Mais ainda, os oficiais poderiam revolver ao seu passado e reincorporar funções típicas da área da segurança e defesa, junto ao judiciário, atendendo, assim, às necessidades decorrentes da determinação do CNJ de instituição das polícias judiciais, passando a assumir funções que, na prática, sempre lhes foram impropriamente designadas ou que lhes cabem executar, mesmo que não detenham meios para tanto, diante dos naturais perigos de seu exercício profissional diário.

Ao fim, deve-se asseverar que as propostas de transformação e incorporação de novas funções detém a finalidade inexorável de propiciar uma melhor prestação do serviço público jurisdicional, na atualidade, bastante desacreditado pela morosidade e burocracia de um poder bastante conservador.

Portanto, transformar a categoria dos oficiais de justiça num novo tipo de agente público, mais alinhado às necessidades sociais atuais, e, igualmente, cada vez mais especializado no exercício especializado de execução de ordens judiciais, certamente, significaria a geração de uma maior capacidade técnica ao judiciário como um todo, e, uma maior efetividade à prestação jurisdicional prometida pela constituição. Significaria, igualmente, o fortalecimento do braço forte (longa manus) do judiciário nas ruas. Significaria, ao fim, conferir novos níveis de eficácia à soberania estatal.

Ademais, deve-se destacar que o presente estudo abre novas possibilidades de continuidade: a análise da percepção de oficiais de justiça atuantes diante de diferentes contextos (urbanos, rurais, de grandes, médias ou pequenas cidades, em diferentes tribunais, dentre outros) a respeito de possibilidades agregáveis as suas respectivas realidades (aliás, conforme os próprios princípios do design thinking); construções de novas possibilidades integrativas do trabalho desses agentes junto aos núcleos de inovação dos tribunais de justiça e demais órgãos componentes do sistema judiciário (Defensoria Pública, Ministério Público, entre outros); e, ainda, o estudo de possíveis agregações tecnológicas simples e acessíveis ao trabalho corriqueiro dos agentes públicos em questão. 


\section{Agradecimentos}

Registra-se o agradecimento aos seguintes grupos de pesquisa e pessoas, por contribuições intelectuais e materiais ao trabalho: a) CROM - Ciência a serviço da gestão pública; b) Érgane - Instituto científico da Amazônia; c) Grupo de estudos $O$ direito do Amanhã; d) Laboratório de Geografia da Violência e do Crime, da Universidade do Estado do Pará; e) Grupo de Pesquisas Métodos e Diagnósticos em segurança pública, da Universidade Federal do Pará; f) a equipe de servidores do Núcleo de Gerenciamento de Resultados, da Secretaria de Estado de Segurança Pública do Pará, Brasil; g) A equipe de servidores e magistrados do Fórum da Comarca de Benevides, Estado do Pará, Brasil, especialmente, a equipe de oficiais de justiça avaliadores local, sempre aberta e participativa de pesquisas científicas e discussões jurídicas.

\section{Referências}

Bardin, L. (2011). Análise de Conteúdo. São Paulo: Edições 70.

Bauman, Z. (2011). Modernidade Líquida. Rio de Janeiro: Zahar.

Bittar, E. C. B. (2016). Metodologia da pesquisa jurídica. 14. Ed. São Paulo: Saraiva.

Brasil (1941). Decreto-lei n. 3.689, de 3 de outubro de 1941. Brasília: Governo Federal.

Brasil (2015). Lei n. 13.105, de 16 de março de 2015. Brasília: Governo Federal.

Brasil (1999). Lei n. 9.883, de 7 de dezembro de 1999. Brasília: Governo Federal.

Brasil (2021a). Câmara dos Deputados. Projeto de Lei n. 1117/2021. Brasília: Governo Federal.

Brasil (2005). Câmara dos Deputados. Projeto de Lei n. 5415/2005. Brasília: Governo Federal.

Brasil (2012). Câmara dos Deputados. Projeto de Lei n. 3722/2012. Brasília: Governo Federal.

Brasil (2020a). Câmara dos Deputados. Projeto de Lei n. 4755/2020. Brasília: Governo Federal.

Brasil (2018). Câmara dos Deputados. Projeto de Lei n. 9719/2018. Brasília: Governo Federal.

Brasil (2019a). Câmara dos Deputados. Projeto de Lei n. 1608/2019. Brasília: Governo Federal.

Brasil (2020b). Câmara dos Deputados. Projeto de Lei n. 6438/2020. Brasília: Governo Federal.

Brasil (2020c). Conselho Nacional de Justiça. Resolução n. 344/2020. Brasília: Governo Federal.

Brasil (2019b). Senado Federal. Projeto de Lei n. 2525/2019. Brasília: Governo Federal.

Brasil (2019c). Senado Federal. Projeto de Lei n. 3713/2019. Brasília: Governo Federal.

Brasil (2021b). Superior Tribunal de Justiça. Acórdão do HC 641.877/DF. Relator: Ministro Ribeiro Dantas. Quinta Turma. Julgado em: 09/03/2021.

Publicado em: 15/03/2021. 2021b. Brasília: Poder Judiciário Federal.

Cepik, M. (2003). Espionagem e democracia: agilidade e transparência como dilemas na institucionalização de serviços de inteligência. São Paulo: FGV.

Coelho, F. A. (2004). Teoria geral do processo. São Paulo: Juarez de Oliveira.

Estado do Pará (2007). Lei n. 6.969, de 9 de maio de 2007. Belém: Governo do Estado do Pará.

Frigotto, G., \& Santos, J. V. (2019). A Revolução 4.0 e a reedição das lógicas das revoluções burguesas. REVISTA IHU, 544(19), 40-46.

Fontanela, C.; Santos, M. I. S. A. S., \& Albino, J. S. (2020). A sociedade 5.0 como instrumento de promoção dos direitos sociais no Brasil. Justiça do Direito, 1 (34), 29-56.

Goodman, M. (2015). Future Crimes. São Paulo: HSM Editora.

Google Maps (2021). Localização do Fórum de Benevides-PA. https://www.google.com.br/maps/place/R.+Paul+Begot,+1+-+Benevides,+PA,+68795-000/@ $1.3631194,-48.2445529,17 \mathrm{z} /$ data $=! 4 \mathrm{~m} 5 ! 3 \mathrm{~m} 4$ !1s0x92a45803ff197439:0x784ac48369416d0b!8m2!3d-1.3629548!4d-48.2442125.

IBGE (2019). Instituto Brasileiro de Geografia e Estatística. PNAD Contínua TIC 2018. https://www.ibge.gov.br/estatisticas/sociais/trabalho/17270-pnadcontinua.html?=\&t=resultados.

Imperio do Brazil (1824). Constituição Política do Imperio do Brazil. Rio de Janeiro: Imperio do Brazil.

Imperio do Brazil (1885). Decreto n. 9420 de 28 de abril de 1885. Rio de Janeiro: Imperio do Brazil. 
Research, Society and Development, v. 10, n. 11, e189101119454, 2021

(CC BY 4.0) | ISSN 2525-3409 | DOI: http://dx.doi.org/10.33448/rsd-v10i11.19454

José, P. (2020). Bitcoin poderia ser bloqueado na hora com novo sistema de penhora lançado pelo Banco Central do Brasil. Cointelegraph. Disponível em: < https://cointelegraph.com.br/news/sisbajud-could-block-bitcoin-balance>. Publicado em: 30.09.2020. Acesso em: 01.03. 2021.

Lima Junior, E. S. (2019). Atualidade do oficial de justiça no brasil. Recomeço, superação e mudança no perfil. Execução Judicial. https://revistaexecucaojudicial.com.br/atualidade-do-oficial-de-justica-no-brasil-recomeco-superacao-e-mudanca-no-perfil.

Mata, V. S.; Costa, C. H. O.; Fernandes, D. C.; Silva E. O.; Cardoso, F. A.; Andrade, J. C.; Rezende, L. P. L.; Oliveira, M. F.; Souza, N.; Machado, P. E. V., \& Rodrigues, R. P. M (2018). Indústria 4.0: a Revolução 4.0 e o Impacto na Mão de Obra. Rev. Cienc. Exatas Tecnol., 13 (13), 17-22.

Nascimento, D. M.; Miranda, W. D., \& Reis Netto, R. M. (2018). Control of legality of the juridical and administrative act practiced in the intelligence activity: the case of the Democratic State of brazilian Law. Pensar, 4 (23), 1-17.

Peck, P. \& Rocha, H. (2018). Advocacia digital. São Paulo: RT.

Peck, P.; Weber, S. T., \& Oliveira Neto, A. A. (2019). Fundamentos dos negócios e contratos digitais. São Paulo: RT.

QR Code Generator (2021). QR code indicativo do Fórum de Benevides-PA. https://pt.rakko.tools/tools/41/.

Reis Netto, R. M.; Chagas, C. A. N., \& Almeida, L. S. (2019). A cooptação de agentes do sistema penitenciário como forma de integração dos presídios às redes territoriais externas do tráfico de drogas no estado do Pará. Ateliê Geográfico, 3 (13), 157-174.

Reis Netto, R. M.; Miranda, W. D.; Gomes, H. W. A. J., \& Chagas, C. A. N. (2018). A legalidade do ato praticado na atividade de inteligência: perspectivas de validade perante o ordenamento jurídico atual. In: Miranda, W. D.; Reis Netto, R. M., \& Santos, L. R. L. Atividade de inteligência e segurança pública: O Brasil e as trincheiras do século XXI Ananindeua/PA: Edições dos Autores.

Reis Netto, R. M., \& Chagas, C. A. N (2019). A percepção dos agentes da segurança pública a respeito enfrentamento ao poder público como estratégia de integração dos presídios às redes externas do tráfico de drogas. In: Trindade, C. M. et al. Segurança Pública: Ética e Cidadania. Curitiba: CRV.

Reis Netto, R. M. \& Miranda, W. D. (2021). A quem interessaria a extinção de carreiras estatais como a dos oficiais de justiça? In: Reis Netto, R. M.; Miranda, W. D., \& Reis, J. F. G. Segurança Pública e Atividade de Inteligência: debates e perspectivas. Ananindeua: CROM, 2021. No prelo.

Ruditz, G.; Nogami, O. (2010). Segurança e Defesa Nacionais: conceitos básicos para uma análise. Rev. bras. polít. int., 1 (53), 1-10.

Simões, R. B.; Reis Netto, R. M.; Miranda, W. D. (2021). Justiça e território: A percepção de oficiais de justiça sobre o risco inerente à prestação material da justiça. In: Reis Netto, R. M.; Miranda, W. D., \& Reis, J. F. G. Segurança Pública e Atividade de Inteligência: debates e perspectivas. Ananindeua: CROM, 2021. No prelo.

Souza, C. A. P., \& Oliveira, J. V. (2019). Sobre os ombros de robôs? A inteligência artificial entre fascínios e desilusões. In: Frazão, A., \& Mulholland, C. Inteligência artificial e Direito: Ética, regulação e responsabilidade. São Paulo: RT.

Techtudo (2021). Seis casos curiosos em que um NFT foi usado. https://www.techtudo.com.br/listas/2021/04/seis-casos-curiosos-em-que-um-nft-foiusado.ghtml. 